Article

\title{
An Analysis of Situations and Perspectives of Secondary Education Korean Dance Teachers' Task Presentation Sustainable Teaching Effectiveness
}

\author{
Eunchang Kwak ${ }^{1, *(\mathbb{D})}$ and Inseon Kwon ${ }^{2}$ \\ 1 College of Physical Education, Kyunghee University, Yongin 17104, Korea \\ 2 College of Art, Kongju National University, Gongju 32588, Korea; iskwon3121@gmail.com \\ * Correspondence: eckwak@khu.ac.kr; Tel.: 82-10-2459-3578
}

check for

updates

Citation: Kwak, E.; Kwon, I. An

Analysis of Situations and

Perspectives of Secondary Education

Korean Dance Teachers' Task

Presentation Sustainable Teaching

Effectiveness. Sustainability 2022, 14,

1762. https://doi.org/10.3390/

su14031762

Academic Editor:

David González-Gómez

Received: 29 November 2021

Accepted: 1 February 2022

Published: 3 February 2022

Publisher's Note: MDPI stays neutral with regard to jurisdictional claims in published maps and institutional affiliations.

Copyright: (C) 2022 by the authors. Licensee MDPI, Basel, Switzerland. This article is an open access article distributed under the terms and conditions of the Creative Commons Attribution (CC BY) license (https:// creativecommons.org/licenses/by/ $4.0 /)$.

\begin{abstract}
The purpose of this study was to investigate the task presentation situations and perspectives of secondary education Korean dance teachers in terms of sustainable teaching effectiveness. The subjects included two teachers with 5 years of experience, two with 6-15 years of experience, and one with more than 16 years of experience. Jazz dance and Korean folk dance were the tasks for the study. For data collection, 20 classes were videotaped by research assistants. Data were analyzed using the Qualitative Measurement Teacher Performance System (QMTPS) and reliability was set to 90. Interviews were also conducted to collect more detailed information on their task presentation. The results of this study show that the less experienced the teacher, the lower their QMTPS scores, as well as their students' attention to and perception of task presentation. Checking for students' understanding of the task was unclear and stereotyped. All teachers indicated that their knowledge on task presentation was very poor and few specified that education was provided during their in-service teacher training programs. The findings indicate that teacher training programs should provide specific information and experience on task presentation for sustainable effective teaching skills.
\end{abstract}

Keywords: task presentation; QMTPS; sustainable teaching skills; effective teaching

\section{Introduction}

Task presentation skills are important for teachers in terms of their teaching effectiveness. Task presentation is defined as an instructional event whereby the teacher delivers information to learners as to "what they are to do and how they are to do it" [1]. Teachers expect students to perform well when presented with a task [2]. However, contrary to the expectations of teachers, the understanding level of students is not always high. The reason for this is that the teacher's task presentation may be vague, of poor quality [3], or delivering a large amount of information at once, leading to students' failing or struggling to understand the task. High-quality task presentation increases students' task adherence, practice time, and achievement [4-6].

Yerg and Twardy [7] attempted to discover the characteristics of effective teaching behavior and found that competent teachers tend to take more time to deliver task information. However, after Rink and Werner [8] highlighted that it is impossible to judge the quality of task presentation from a simple temporal point of view, they developed the Qualitative Measurement Teacher Performance System (QMTPS) to evaluate the qualitative efficiency of task presentation [9]. Following these studies, further effort was devoted to clarifying the conditions for presenting various tasks affecting student performance. For example, Kwak [10] explored the teaching of a lacrosse overhand throwing task for middle school students, where the group was provided with simple and clear explanations, repetitive full demonstrations, use of learning cues, oral and visual rehearsals, performed movements, and memory intelligence. The task presentation group showed superior exercise performance ability compared with the other groups. The findings indicated that 
specific conditions should be met to achieve high-quality task presentation. These results are consistent with the accuracy of movement performance and information memory in high school students' shotput movement learning [11] and dance movement learning [12], and elementary school students' expression activity movement learning [13]. Those studies have revealed that the specific task presentation conditions applied in the abovementioned studies were the best.

Previous studies $[4,10-13]$ have consistently found that succinct verbal explanation, full and repetitive demonstration, and learning cues and rehearsals, regardless of the grade and type of task, have a positive effect on improving students' achievement when presenting tasks. However, most teachers lack accurate behavior demonstrations or fail to provide learning cues, and the learning atmosphere is often disruptive; thus, students cannot perform the tasks properly [3]. This is thought to be due to field teachers' indifference to presenting tasks and their insufficient ability to develop such a skill. Nevertheless, research has revealed the possibility of improving the presentation ability in actual classes [11-13]. For example, Hall et al. [14] studied the task presentation of 15 prospective physical education teachers in southeastern U.S. universities and found that the performance of students who received high-quality task presentation was superior to those who did not. This finding shows that the ability to present tasks can be improved by experience in teaching task presentation. Rhoades and Woods [4] also indicated that QMTPS scores are consistent with quality instruction, which can positively affect student achievement. A total score of 55 or higher was an indicator of effective task presentation skills and student achievement [15]. The National Board Professional Teaching Standards (NBPTS) in the U.S. states that "teachers know the subjects they teach and how to teach those subjects to students" [16]. Whereas the literature on task presentation is highly contextualized and not in dance settings, the findings indicate that the program for National Board Certified Physical Education Teachers (NBCPETs) [16] and the College Board (CB) [17] may be able to influence student achievement in dance programs.

Operationalizing these efforts through rigorous assessments of dance teachers' task presentation of key competencies in teaching is another evolving task for sustainable dance education leaders. Although the number of sustainability programs in higher education has grown significantly [17], little attention has been given to sustainability development programs for dance teachers in Korea, which necessitates greater effort [18]. From this perspective, several frameworks of teaching competency in sustainability [19-22] can provide valuable insights for future Korean dance teacher education programs.

In dance academia, where information on task presentation is almost completely lacking, information gained in the field of physical education will be meaningful. The effect of the characteristics of task presentation on academic achievement have been revealed by age and tasks [12,13], but the real situation and perspectives of teachers regarding task presentation have not been examined in detail. Therefore, the purpose of this study was to analyze the perspectives and the actual situation of task presentation for middle school dance teachers in Korea.

\section{Materials and Methods}

Sample and Data Collection

To analyze the actual condition of secondary dance teachers' task presentation, five dance teachers from five middle schools located in H-city, Gyeonggi Province, Korea, were selected for the study. Subjects were selected after verbally agreeing that they would participate in the study; they included two teachers (teachers A and B) with 5 years or less of educational experience, two teachers (teachers $C$ and D) with 6 to 15 years' experience, and one teacher (teacher E) with more than 16 years' experience. Originally, the subjects of the study consisted of two teachers per career stage, but one highly experienced teacher left the study on the grounds of the burden of classes starting, leaving a total of five subjects. Subject names were converted to acronyms to protect their identities and maintain objectivity. This study complies with the ethical requirements of the body that subsidized 
the research, meaning an agreement was signed based on Organic Law 15/1999 on Data Protection. No additional approval was required for the research as the data obtained do not involve animal or clinical experimentation.

For data collection, in-depth interviews with teachers and four dance classes for each were videotaped ( 20 classes in total). In-depth interview data were collected through expert meetings, and the questionnaire was revised and supplemented through pretesting. Interviews were conducted in the counseling room and subject council room where the subjects felt comfortable, and all interviews were recorded using a voice recorder. All recorded interview contents were transcribed verbatim. Teachers were asked to conduct regular teaching in the dancing room; Teachers $\mathrm{A}, \mathrm{D}$, and $\mathrm{E}$ conducted jazz dance classes, and Teachers $\mathrm{B}$ and $\mathrm{C}$ conducted folk dance classes based on their curriculum. The class was filmed using a camera and a wireless microphone, and the collected data were analyzed through QMTPS. For the analysis of qualitative teaching behavior, an expert group was formed and the instructional video of the first session was jointly analyzed. In the case of ambiguous behavior, ground rules were applied through expert group meetings to increase the reliability of qualitative instructional behavior analysis.

\section{Research Tools}

\subsection{In-Depth Interview}

In this study, in-depth interviews were conducted in advance, and the interview questionnaire was developed through the following steps: First, to grasp the knowledge and degree of application of task presentation of secondary dance teachers, the elements of task presentation were defined as "attention", "verbal explanation", "demonstration", "learning cues", and "assessment knowledge". A learning cue is a word or short phrase that identifies the critical elements or features of a motor skill or task [5]. Learning cues call the learner's attention to key elements of a skill and project a clear visual image of a skill for the learner. Learning cues play a role in guiding students' preparation for action and provide the link between actions.

Through interviews, we asked about the effective methods used by individual teachers for task presentation in actual classroom situations. If there was insufficient experience and knowledge on task presentation, we asked for expertise regarding effective task presentation. If the task presentation was not clearly explained, it was judged that understanding of task presentation was not enough based on a pedagogy expert's decision. Lastly, subjects were asked whether they would undertake pedagogical training for task presentation in the future, and the necessity of methods for teaching task presentation. The pre-in-depth interview questionnaire was reviewed through expert meetings for its suitability and applicability, and then revised and supplemented to create the final questionnaire.

\subsection{Qualitative Teaching Behavior Measurement Tool}

In this study, the QMTPS designed by Rink and Werner [8] was used to analyze teaching behavior. Yerg and Twardy [7] found that competent teachers tend to provide longterm task presentation. However, Werner and Rink [9] argued that it was not appropriate to decide on an efficient task presentation over time. From this perspective, QMTPS was developed to measure qualitative teaching behavior and can be used to analyze effective teaching behavior between teachers [9].

Gusthart, Kelley, and Rink [23] found that the QMTPS composite average is a valid measure of teaching efficiency. They argued that a score of 55 or higher is an effective indicator of task presentation, and that if a teacher delivers a task presentation with a score of 55 or more, student achievement is considered to be higher. We supplemented and used the existing QMTPS to measure the degree of student attention, a prerequisite for task presentation. In other words, to understand the students' degree of attention, the number of problematic behaviors, such as touching the tools or placing their gaze in other places, was measured by observing the students' actions when delivering the teacher's task presentation. These figures were reflected in the QMTPS score to determine the attention level of the students when the teacher delivered the task. In addition, the type and direction of the demonstration were used 
to obtain more detailed information on the actual conditions of the demonstration by the teachers. Existing teacher clarity and feedback items were excluded from this study because less than five times of the frequency means little happens in the classroom.

\section{Data Analysis}

In-depth interviews recorded beforehand were categorized. The variables categorization was divided into attention, verbal explanation, demonstration, learning clues, and task presentation education; other content was classified and recorded as "other". To ensure the reliability of the analysis of teaching behavior, a reliability test was conducted through an expert group consisting of a researcher, two master's degree students in dance education, and one doctoral student. The definition of task presentation behavior was classified, and the reliability between observers was verified five times through the coincidencedisagreement reliability coefficient to ensure the degree of agreement of the four observers. The final reliability was $91 \%$. The frequency of each item of the QMTPS in the four classes for each teacher obtained using the QMTPS analysis frame was calculated and recorded as a percentage, and finally, the total QMTPS score for each teacher was calculated.

\section{Results}

\subsection{Student Attention}

We analyzed students' attention through the QMTPS when teachers were presenting a task. Teacher E scored highest at $88.9 \%$, followed by teacher D $(66.6 \%)$, teacher C $(63.6 \%)$, teacher B (52.8\%), and teacher A (40\%). The average of the five teachers was $62.2 \%$, indicating that about 4 out of 10 teachers' task presentations were ineffective (Table 1).

Table 1. Frequency and percentage of student attention for five teachers (Teacher A-E).

\begin{tabular}{ccccccc}
\hline & A & B & C & D & E & Total \\
\hline Yes & $4(40)$ & $19(52.8)$ & $14(63.6)$ & $8(66.6)$ & $16(88.9)$ & $61(62.2)$ \\
Partial & $5(50)$ & $13(36.1)$ & $6(27.3)$ & $2(16.7)$ & $2(11.1)$ & $28(28.6)$ \\
No & $1(10)$ & $4(11.1)$ & $2(9.1)$ & $2(16.7)$ & $0(0)$ & $9(9.2)$ \\
\hline
\end{tabular}

\subsection{Demonstration}

From the analysis of dance teachers' demonstrations by QMTPS, the proportion of a full demonstration by teachers was $50 \%$ for teacher A, $83.3 \%$ for teacher $\mathrm{B}, 54.5 \%$ for teacher C, $16.7 \%$ for teacher $\mathrm{D}$, and $72.2 \%$ for teacher $\mathrm{E}$, for an average of $63.3 \%$. The proportion of a partial demonstration was: teacher A, $20 \%$; teacher B, $0 \%$; teacher $C, 13.7 \%$; teacher D, $8.3 \%$; and teacher E, $27.8 \%$, resulting in an average of $11.2 \%$. Frequencies of demonstration for teachers A, D, and E were 10,12, and 18, being less than those of teachers B and C. Teacher A presented a full demonstration five times, a partial demonstration two times, and only verbal explanations without a demonstration three times. Conversely, teachers $B$ and $C$ showed a relatively high proportion of total demonstration, and only provided verbal explanations six and seven times, respectively. The total proportion of cases without a demonstration was also high at $25.5 \%$. There were few teachers who applied various directions while showing demonstration to students. The results of this study show that demonstration using various directions had very limited frequencies (Table 2).

Table 2. Frequency and percentage scores for demonstration category by teachers A-E.

\begin{tabular}{cccccccc}
\hline & & A & B & C & D & E & Total \\
\hline & Full & $5(50)$ & $30(83.3)$ & $12(54.5)$ & $2(16.7)$ & $13(72.2)$ & $62(63.3)$ \\
Demonstration Type & Partial & $2(20)$ & $0(0)$ & $3(13.7)$ & $1(8.3)$ & $5(27.8)$ & $11(11.2)$ \\
& No & $3(30)$ & $6(16.7)$ & $7(31.8)$ & $9(75)$ & $0(0)$ & $25(25.5)$ \\
\hline Various Demonstration & Yes & $3(30)$ & $3(8.3)$ & $2(9.1)$ & $0(0)$ & $1(5.6)$ & $9(9.2)$ \\
Directions & No & $7(70)$ & $33(91.7)$ & $20(90.9)$ & $12(100)$ & $17(94.4)$ & $89(90.8)$ \\
\hline
\end{tabular}




\subsection{Learning Cues}

By analyzing the frequency of the presentation of learning cues, the rate of presenting an appropriate number of learning cues was found to be $43.9 \%$. The rate of providing two or more learning cues was $12.2 \%$, and the rate of not providing any cues at all was $43.9 \%$ (Table 3). We found that $56.1 \%$ of teachers provided an inappropriate number of learning cues during class, indicating that the learning cues were not well-understood. By analyzing the quality of learning cues, we found that $52 \%$ of teachers did not provide information at an appropriate level, including demonstration and explanation.

Table 3. Frequency and percentage scores for the learning cue category by five teachers.

\begin{tabular}{cccccccc}
\hline & & A & B & C & D & E & Total \\
\hline \multirow{4}{*}{ Learning Cue } & $3-4$ & $0(0)$ & $0(0)$ & $3(13.6)$ & $5(41.7)$ & $4(22.2)$ & $12(12.2)$ \\
& $1-2$ & $5(50)$ & $9(25)$ & $13(59.1)$ & $4(33.3)$ & $12(66.7)$ & $43(43.9)$ \\
& None & $5(50)$ & $27(75)$ & $6(27.3)$ & $3(25)$ & $2(11.1)$ & $43(43.9)$ \\
\hline
\end{tabular}

\subsection{Comprehensive QMTPS Analysis}

A total QMTPS score of 55 or higher is an indicator of effective task presentation, and it was reported that student achievement is higher when a teacher's task presentation score is 55 or higher [23]. As a result of analyzing 40 classes taught by five teachers in this study, the average qualitative teaching behavior score was 54.4 (Table 4). When considering the standard of efficient teaching behavior as 55 points, the difference between high and low scores was found to be large, more than 30 points. In this study, we found that the overall average value of QMTPS of the five teachers was slightly less than the effective task presentation standard $[5,6,23]$.

Table 4. Average QMTPS scores within categories and overall.

\begin{tabular}{ccccccccc}
\hline & $\begin{array}{c}\text { Student } \\
\text { Attention }\end{array}$ & $\begin{array}{c}\text { Student } \\
\text { Response }\end{array}$ & $\begin{array}{c}\text { Demo } \\
\text { Type }\end{array}$ & $\begin{array}{c}\text { Demo } \\
\text { Direction }\end{array}$ & $\begin{array}{c}\text { Number of } \\
\text { Cues }\end{array}$ & $\begin{array}{c}\text { Accuracy } \\
\text { of Cues }\end{array}$ & $\begin{array}{c}\text { Qualitative } \\
\text { Cues }\end{array}$ & $\begin{array}{c}\text { Average } \\
\text { QMTPS }\end{array}$ \\
\hline Good & 62.2 & 77.6 & 63.3 & 9.2 & 43.9 & 42.8 & 48 & 54.4 \\
Ok & 28.6 & 0 & 11.2 & 0 & 12.2 & 10.2 & 0 & 45.6 \\
Bad & 9.2 & 22.4 & 25.5 & 90.8 & 43.9 & 47 & 52 & \\
\hline
\end{tabular}

\section{Discussion}

From the in-depth interviews, we found that teachers A and B-the novice teacherswere not particularly effective at capturing students' attention. All teachers revealed that they learned the methods of senior teachers through class observation when they were novice teachers, indicating that task presentation was not properly taught in the teacher training program. In general, teachers strive to focus their students' attention in class, but are not confident in their strategies and feel pressure to proceed quickly. They may even create a coercive atmosphere to attract students' attention. For example, showing charisma through strict and scary images can be the product of an unsystematic dance teacher education. Teacher education programs should provide actual specific teaching experiences and learning. Especially, teaching skills need a lot of time to become acquainted with. However, current teacher education programs in Korea seldom provide enough opportunity to practice specific teaching skills and knowledge for effective teaching [11-13].

As a result of analyzing teachers' ability to capture student attention, we revealed that teachers $A$ and $B$, who were novice teachers, did not receive any training on how to concentrate and present tasks in the teacher training process. Conversely, intermediate or highly experienced teachers revealed that they indirectly acquired the strategy of capturing attention through self-directed effort and experience, senior teachers, or self-training to engage their students' attention. Attempting to capture attention using the promised procedure before presenting the task increases the clarity of teaching behavior while 
also clarifying the task delivery. The clarity of task presentation has a direct effect on student and task presentation; in a well-focused state, it contributes to higher academic achievement [3,11-13]. Therefore, considering students' attention is an important factor for securing and improving the clarity of task presentation, and strategic approaches toward this should be a focus of the teacher education program.

Though the proportion of a full demonstration was high overall, in the in-depth interviews, the teachers' perceptions of full and partial demonstration were different. Some teachers reported that full demonstration is used to increase the continuity of motion and students' understanding of movements, while others answered that providing important information about motion through a partial demonstration alone is effective; the perceptions of the latter are different from prior research results [10-12], which indicate that full demonstration is more effective for task achievement.

The reason for providing a demonstration is to help students understand and perform the task effectively. The results of the study by Landers and Landers [24] can be used as the basis for whether a teacher's direct demonstration or a student's demonstration is more effective. By comparing teachers and students as demonstrators using Bachman ladder climbing, they revealed that the group observing experienced teachers performed best, revealing differences according to the status of demonstrators. A Bachman ladder task is used for motor learning area and physical education. It requires climbing ability. The ladder is free standing (there is no support), therefore participants were required to balance themselves while ascending the rungs of ladder. This task was chosen for its challenge, feasibility, and ecological validity. Also, the task allows a precise measurement of the participants' performance.

However, a relatively recent comparison of the accuracy of demonstrations for teachers and student models revealed that the important thing was not the status of teachers or students, but the skill level and accuracy of demonstrators. Feltz [25], who proved the power of visual effects, revealed that regardless of age, providing more demonstrations is more effective when teaching task performance than fewer or no demonstrations. If we consider the actual frequency of demonstrations, we found that some teachers provided demonstrations 2-3 times per hour of class; on the other hand, some teachers provided demonstrations by regrouping students only when they experienced difficulties or made mistakes when performing tasks. However, it is necessary to repeatedly provide a demonstration when the students' task performance level is low, no matter how clearly the task presentation is provided.

These results are consistent with the in-depth interviews, where teachers reported difficulty in providing a demonstration that requires more than two repetitions. Although the teachers agreed with the need to provide students with a different direction of the demonstration, in reality, they were providing a one-time demonstration in one direction without considering the qualitative aspect of the demonstration and the level of understanding of the students. They answered that the reason for not showing the different directions during the demonstration is that it is difficult to understand when the movements are complicated, but in reality, they showed a dual attitude that prioritized their convenience. Teachers reported that it is difficult to repeat a demonstration more than two times. In addition, only actions that are judged to be complex or difficult tasks are selectively shown. Some teachers took videos from different angles and showed them, or compared them with the wrong movements because they remembered the movements that students often make mistakes on and believed that by showing these to students, they can easily see the difference. As such, when presenting a task, teachers selectively used the action only when it was difficult for students to understand the task, rather than by various demonstrations. However, they agreed that it was easier for students to understand when the demonstration was provided under different circumstances and conditions. The following are examples of comments from dance teachers: 
Usually I show a demonstration 2 or 3 times. However, we watch students' reactions and show them repeatedly if they do not understand the task. If students don't understand what I've explained, I think they should do it again. (Teacher B)

Shows when first given to tasks and when needed individually. In the middle, it loops through the students doing their tasks, and if too many students find the tasks difficult or poor, they are reassembled and provided repeatedly. (Teacher C)

Both the teacher demonstration and the student demonstration have their pros and cons, and although effective demonstrations vary depending on teaching method and content, I think teacher demonstration is more effective. In the case of student demonstration, if a student makes a mistake, the students can get a sense of wonder. (Teacher A)

Even during the in-depth interviews, most teachers did not specifically plan the learning clues or only made a rough plan, showing indifference regarding learning cues.

Therefore, the provision of learning cues is a useful strategy for performing complex functions from the standpoint of students who cannot receive the teacher's attention and feedback in physical education classes comprising many students [26]. It has been consistently proven in previous studies that the effects of learning cues provided in task presentation contribute to functional performance and cognitive ability improvement [10-13]. However, this study revealed that teachers do not systematically plan learning cues for each class, and only provide important words or sentences to students through their classroom experiences and prior knowledge. The unsystematic use of learning cues leads to a sudden inability to recall or speak about the learning cues. Students who are not provided with learning cues have difficulties in performing tasks due to a lack of information on the core content necessary for task performance. The content showing teachers' perceptions related to learning cues are as follows:

No study cues were planned. I didn't plan in detail because I know from my class experience which assignments are the most needed points. (Teacher B)

I tend to think about the most important elements of movement in my head. But when I can't think of an important word, it's hard. In a classroom class, you can briefly look at a textbook or tutorial and explain, but we can't. Sometimes I can't remember. (Teacher C)

Teachers did not systematically use learning cues in terms of the provision of an appropriate number of learning cues, accuracy of cues, and qualitative cues, which means they lacked an understanding of learning cues. Rink [5,6] suggested that middle and high school students should have less than 3-4 teaching cues based on their limited cognitive ability and memory capacity. Such unorganized learning cues and lack of planning lead to the prediction that the teaching-learning process may be neglected. This finding was confirmed in the analysis of the physical education class task presentation of excellent elementary school physical education instructors and novice teachers [27], and the task presentation behavior analysis of physical education teachers through qualitative teaching behavior analysis. This study revealed that teachers do not provide quality learning cues due to low understanding. If students are not provided with learning cues, they will experience difficulties in performing the task due to the lack of information on the most important core content when performing the task. Additionally, we cannot rule out situations in which false information is provided or overlooked. Considering their positive effect on students' task performance, the planned and systematic use of learning cues is essential.

By analyzing the actual situation of task presentation, we found that teachers lacked knowledge and confidence in task presentation because they had no learning experience with it during their teacher training program. In the current teacher training course or re-education course in Korea, there is no specific education provided on the theory and practice of task presentation, which can cause serious setbacks in the performance of the teacher's function. All teachers are expected to have appropriate teaching skills, but in reality, this is not the case. There are even teachers who say that the term "task presentation" is unfamiliar, indicating that special guidance is urgently needed. Task presentation is 
carried out during the introduction or progression of tasks in each class; however, it was observed that teachers do not have any learning experience with it in the teacher training program, causing them to feel helpless when delivering task presentations. Delivering task presentations is unavoidable in the process of introducing or proceeding with the tasks in each class. For field teachers, a lack of self-confidence, anxiety, and withdrawal are factors that make them unable to contribute to the academic achievement or growth of students. The content showing the perceptions of teachers regarding task presentation is as follows:

First of all, I'm not sure which teaching method is effective in theory because I never learned it at university and only studied it to prepare for the teacher certification exam. (Teacher B)

It seems to be too difficult to judge based on my personal judgment and accumulated experience. I think that I lack knowledge about the way of delivering task presentation that I did inadvertently. (Teacher C)

Regarding whether to take part in an educational program on task presentation, all five teachers indicated a willingness to take a course. Teachers expect an educational program where they can learn about effective task presentation, engage in discussion with fellow teachers, share knowledge, and apply it in their teaching. The followings are comments from dance teachers:

I want to learn effective teaching methods and I think there is a need for a program that can be shared with fellow teachers about practical methods. Theory is important, but it seems that more in-depth education is needed on how to apply it. (Teacher C)

It would be nice if it could be taught in a more systematic way, rather than in a fistfighting way. There is no right answer to education, but if I can teach students more efficiently and effectively, I would like to take the course. (Teacher D)

If such a re-education program is provided, a much more efficient teaching-learning process could be achieved. For example, a study on the status of task presentation of 15 preparatory physical education teachers at Eastern University in the United States supported the need for a task presentation education program [14]. In that study, when comparing between preparatory gymnastics teachers who received task presentation education and preparatory physical education teachers who did not receive task presentation education, those that received task presentation education performed more tasks than any other groups. The results of this study emphasize the necessity of providing practical education programs related to task presentation as the basis of teacher re-education programs through the testimonies of field teachers. Although this study was limited to five dance teachers, it shows that Korean dance teachers' understanding of task presentation is low, and its use by dance teachers in the field is either sloppy or through personal experience. Our findings indicate that practical task presentation education is necessary to improve the teaching ability of dance teachers, and teacher training institutions should provide task-presentation-specific learning and experience to increase its practical use in the field. Nadeem and Rahman [28] suggested that teacher training on task presentation has a longlasting impact on their professional life even after their formal education. Therefore, this study shows that there is an urgent need to improve teachers' understanding and practice of effective task presentation. It should not be ignored that effective teaching behavior is not improved by mere experience and should be achieved through a sustainable effort to improve teaching effectiveness.

Teacher effectiveness determines the methods of education, the learning environment, and the level of learning; by confirming the resulting student performance, a teacher can improve their teaching abilities. Wiek et al. [20] confirmed that normative competence is important for delivering quality teaching for student learning. In Korea, dance programs in secondary education have provided a limited resource for students $[12,13]$. Despite a growing international community of education sustainability researchers pursuing similar goals, teacher education institutions in Korea do not provide responsive mentorship. 
Dance teacher education programs lack guidance on teaching competencies, while dance teachers lack effective teaching skills. This lack of teachers' competencies causes various problems. The decline in the competitiveness of dance teachers limits the growth and achievement of students. Therefore, their desire and efforts to improve are absolutely necessary. Recently, Kwon [19] and other scholars [29,30] suggested that competencies are not naturally developed in the teaching-learning environment; instead, they require targeted and ongoing efforts by working with the set of concepts, methods, and skills for each competency. Through better understanding of task presentation, the other dimensions of practice theory and their materials require further empirical exploration in the context of task presentation and the professionalized practice of sustainability in Korea. A key implication for practice is to offer teacher development programs and build shared literacy around key competencies. Teacher education programs need to introduce preservice students to available sources and should focus on all dimensions of effective teaching as part of their professional development. Thus, it is necessary to actively introduce sustainability in the dance major programs in Korea. The adoption of sustainable education professional development programs that offer a multitude of benefits [19] is critical and contributes to effective teaching skills.

This study has the following limitations. First, the subjects of this study were five middle school dance teachers in the part of region in Korea, of which two are low-career teachers, two are middle-career teachers, and one a high-career teacher. Since teachers were classified only as dance teaching careers, there is a limit to generalization, so diversity on dance majors, other schools, or regional differences should be considered. Second, the tasks of this study were limited to two categories: jazz dance and fork dance. Therefore, it is necessary to consider the fact that the effect of presenting tasks that may affect different tasks is unknown. Third, since the class environment was all conducted in the dance hall, it may be different from the effects of other learning environments such as auditoriums and gymnasiums.

\section{Conclusions and Suggestions}

The results of this study show that education and practical experience are important to increase sustainable teaching effectiveness in teacher education institutions. The conclusions reached from investigating the need for a re-education program to present professional tasks for in-service teachers are as follows:

1. A sustainable professional task presentation program is needed for preservice teachers and incumbent teachers. In this study, the overall average QMTPS score was 54.4, indicating an inefficient level of task presentation in our cohort. These findings emphasize the need for a professional education program for task-presentation-related expertise and application, revealing that teachers lack both theoretical and application knowledge of task presentation. Fortunately, all of the teachers in this study showed an active intention to participate in a task presentation training program. Since teacher training programs on task presentation will become a forum where teachers can learn, discuss, and share task presentation methods with fellow teachers, it is necessary to actively guarantee the quality of these programs.

2. The following points outline strategies and the need for follow-up studies. First, a study should be conducted to reveal the relationship between teachers' various attention- capturing strategies and students' understanding. Teachers' attention strategies are diverse and creative. If effective attention strategies are revealed through future studies, a strategy for task presentation can be constructed and contribute to its improvement. Second, further research is also needed on the effect of qualitative differences in the demonstration, including the direction and angle of the demonstration, on learning.

Author Contributions: Conceptualization, I.K.; methodology, E.K.; I.K.; formal analysis, I.K.; investigation, E.K.; I.K.; resources, E.K.; I.K.; data curation, writing—original draft preparation, writingreview and editing; visualization, supervision, and project administration, E.K. All authors have read and agreed to the published version of the manuscript. 
Funding: This research received no external funding.

Institutional Review Board Statement: Not applicable.

Informed Consent Statement: Not applicable.

Conflicts of Interest: The authors declare no conflict of interest.

\section{References}

1. Rink, J. Task presentation in pedagogy. Quest 2004, 46, 270-280. [CrossRef]

2. Rink, J. Teaching Physical Education for Learning, 8th ed.; McGraw-Hill: New York, NY, USA, 2020.

3. Uddin, K.S.; Qutoshi, B.; Khan, H.K. The Perceptions and Practices of University Students and Teachers about Classroom Presentations. J. Educ. Educ. Dev. 2020, 7, 269-285.

4. Rhoades, J.; Woods, A.M. National board certified physical education teachers task presentations and learning environments. J. Teach. Phys. Educ. 2012, 31, 4-20. [CrossRef]

5. Rink, J. Teacher effectiveness in physical education-Consensus? Res. Qual. Exerc. Sport 2014, 85, 282-286. [CrossRef]

6. Rink, J. Measuring teacher effectiveness in physical education. Res. Qual. Exerc. Sport 2013, 84, 407-418. [CrossRef] [PubMed]

7. Yerg, B.; Twardy, B. Relationship of specified instructional teacher behaviors to pupil gain on a motor skill task. In Studying the Teaching in Physical Education; Peiron, M., Cheffers, J., Eds.; AIESEP: Liège, Belgium, 1978; pp. 61-68.

8. Rink, J.; Werner, P. Qualitative measures of teaching performance scale. In Analyzing Physical Education and Sport Instruction, 2nd ed.; Darst, P.W., Zakrajsek, D.B., Mancini, V.H., Eds.; Human Kinetics: Champaign, IL, USA, 1989; pp. $269-275$.

9. Werner, P.; Rink, J. Case studies of teacher effectiveness in second grade physical education. J. Teach. Phys. Educ. 1989, 8, 280-297. [CrossRef]

10. Kwak, E.C. The Immediate Effects of Task Presentation Conditions on Middle School Students' Lacrosse Overhand Throw. Ph.D. Thesis, University of South Carolina, Columbia, SC, USA, 1993.

11. Choi, D.M. The Effects of Different Task Presentation Conditions of Students' Performance of Shotput Skill Learning. Ph.D. Thesis, Korea National University of Athletes, Seoul, Korea, 1998.

12. Sim, G.Y. A Study on the Effects of Task Presentation Conditions on Students' Performance in Korean Traditional Dance. Ph.D. Thesis, Kyunghee University, Seoul, Korea, 2012.

13. Kim, S.Y.; Kwak, E.C. The immediate effects of various task presentation conditions on elementary students' performance of expressive movement activities. J. Korean Sport Pedagog. 2015, 22, 85-101.

14. Hall, T.J.; Heidorn, B.; Welch, M. A description of preservice teachers' task presentation skills. Phys. Educ. 2011, 68, 188-198.

15. Gusthart, J.L.; Kelley, I.W. Teachers' instructional variables in volleyball and students' improvement in motor skill. Percept. Mot. Ski. 1993, 76, 1015-1024. [CrossRef] [PubMed]

16. National Board for Professional Teaching Standards (NBPTS). NBCT Certification Renewal: Profile of Professional Growth. Available online: http://nbpts.org/sites/dafault/files/documents/Candicate-Center/ProfileProfGrowth20130408.pdf (accessed on 8 April 2013).

17. The College Board. (2013) International Standards for Arts Education: A Review of Standards, Practices and Expectations in Thirteen Countries and Regions. Available online: http:/ / www.nationalartsstandards.org/content/national-core-arts-standards2 0130828.pdf (accessed on 28 August 2013).

18. Vincent, S.; Rao, S.; Fu, Q.; Gu, K.; Huang, X.; Lindaman, K.; Mittleman, E.; Nguyen, K.; Rosenstein, R.; Shu, Y. Scope of Interdisciplinary Environmental, Sustainability, and Energy Baccalaureate and Graduate Education in the United States; National Council for Science and the Environment: Washington, DC, USA, 2017.

19. Kwon, I.S. Analysis of key competencies and curriculum expertise of Korean dance programs to assist in their long-term sustainability. Sustainability 2021, 13, 5801. [CrossRef]

20. Johnson, E.; Edwards, D.; Simon, J. The Falk School of Sustainability and Environment; Chatham University: Pittsburgh, PA, USA, 2019.

21. Sterling, S.; Glasser, H.; Rieckmann, M.; Warwick, P. "More than scaling up": A critical and practical inquiry into operationalizing sustainability competencies. In Envisioning Futures for Environmental and Sustainability Education; Corcoran, P.B., Weakland, J.P., Wals, A.E.J., Eds.; Wageningen Academic Publishers: Wageningen, The Netherlands, 2017; pp. 153-168.

22. Wiek, A.; Withycombe, L.; Redman, C.L. Key competencies in sustainability: A reference framework for academic program development. Sustain. Sci. 2011, 16, 13-29. [CrossRef]

23. Brundiers, K.; Barth, M.; Cebrian, G.; Cohen, M.; Diaz, L.; Doucette-Remington, S.; Dripps, W.; Habron, G.; Harre, N.; Jarchow, M.; et al. Key competencies in sustainability in higher education-toward an agreed-upon reference framework. Sustain. Sci. 2021, 16, 13-29. [CrossRef]

24. Barth, M.; Rieckmann, M. Academic staff development as a catalyst for curriculum change towards education for sustainable development: An output perspective. J. Clean. Prod. 2012, 26, 28-36. [CrossRef]

25. Gusthart, J.L.; Kelley, I.M.; Rink, J.E. The validity of the qualitative measures of teaching performance scale as a measure of teacher effectiveness. J. Teach. Phys. Educ. 1997, 16, 196-210. [CrossRef]

26. Landers, D.M.; Landers, D.M. Teachers versus peer models: Effects of model's presence and performance level on motor behavior. J. Mot. Behav. 1973, 5, 129-139. [CrossRef] [PubMed] 
27. Feltz, D.L. The effects of age and number of demonstrations on modeling of form and performance. Res. Q. Exerc. Sport 1982, 53, 291-296. [CrossRef]

28. Landin, D. The Role of Verbal Cues in Skill Learning. Quest 1994, 46, 299-313. [CrossRef]

29. Lee, H.S. A comparative study of instructional skills in physical education between effective and beginning elementary school teachers. Korean J. Phys. Educ. 2004, 43, 313-322.

30. Nadeem, M.; Rahman, A. Tackling oral communication skills' enigma through presentation at higher education. Asian J. Soc. Sci. Humanit. 2013, 2, 222-229. 